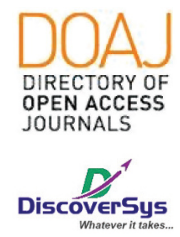

Published by DiscoverSys

\section{Pediatric amyand hernia : case report in Sanjiwani Gianyar Hospital Bali Indonesia}

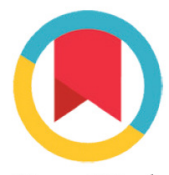

CrossMark

\author{
Luciana $^{1 *}$, Gede Eka Rusdi Antara ${ }^{2}$, Made Dwi Yoga Bharatha ${ }^{3}$
}

\section{ABSTRACT}

Introduction: Amyand's hernia (AH) is defined as protrusion of the vermiform appendix in an inguinal hernia sac, and incidence was reported only $1 \%$ of all inguinal hernias. This study aimed to share the experience of inguinal hernia repair with appendectomy for Pediatric case with non inflamed appendices.

Case: A 2-year-old male came to the emergency department with a history of irreponible lump along with right scrotal tender 6 hours before admission and progressively increased. There is no specific sign of obstruction,dehydration or infection. His lump already presented since new born but with age progression the reponible complain become more frequently. Based on clinical presentation this patient did open repair of hernia as diagnostic and therapeutic, identification of appendix was non-inflamed appendix inside right scrotum, no sign of incarcerated strangulated of perforated. No Complication was reported until two-month post-operative. Surgical correction is already done with non-complication postoperative care for 2 month period.

Conclusion: Pediatric Amyand Hernia is rare case (1\% from all inguinal hernia) diagnostic and therapeutic could be very challenging. Open herniotomy repair and appendectomy for this case was taken with satisfying outcome.

Keywords: pediatric, inguinal hernia, appendectomy.

Keywords: pediatric, inguinal hernia, appendectomy

Cite This Article: Luciana., Antara, G.E.R., Bharatha, M.D.Y. 2019. Pediatric amyand hernia : case report in Sanjiwani Gianyar Hospital Bali Indonesia. Intisari Sains Medis 10 (2): 485-488. D0I: 10.15562/ism.v10i2.511

${ }^{1}$ General Surgery Resident School of Medicine Udayana University, Sanglah General Hospital Denpasar, Bali, Indonesia ${ }^{2}$ Department of Digestive Surgery School of Medicine Udayana University, Sanglah General Hospital Denpasar, Bali, Indonesia ${ }^{3}$ Department of Digestive Surgery,Sanjiwani General Hospital Gianyar , Bali, Indonesia

*Corresponding to: Liciana; ' ${ }^{1}$ General Surgery Resident School of Medicine Udayana University, Sanglah General Hospital Denpasar, Bali, Indonesia. dr.lucy_lucas@yahoo.co.id

Received: 2019-05-06 Accepted: 2019-07-28 Published: 2019-08-01

\section{INTRODUCTION:}

Amyand's hernia is defined as when the appendix is trapped within an inguinal hernia. While the incidence of this type of hernia is rare, the appendix may become incarcerated within Amyand's hernia and lead to further complications such as strangulation perforation or Incarceration. ${ }^{1}$

Amyand's hernia is named after Claudius Amyand, who, on December 6, 1735, performed the first successful appendectomy during the treatment of an 11-year-old boy who presented with a right inguinal hernia. During the surgery, Amyand found a pin within the appendix, which was encrusted with stone; the appendix was found within the inguinal hernia sac. ${ }^{2-4}$ The term Amyand's hernia therefore refers to an incarcerated hernia containing appendix, which may be normal or inflamed. ${ }^{4}$ Because of the rarity of the condition, the term "Amyand's hernia" been recently adopted as an eponymous description of an incarcerated appendix within an inguinal hernia.

Because the incidence of this disease is so rare that there is no therapeutic recommendation or a clinical trial favored for the gold standard therapy for this disease, moreover, there is still controversy regarding the action of appendectomy for normal appendix or mesh use when performing hernia repair if an appendectomy is performed. In this case report, we try to elaborate Amyand's hernia type 2 case managed with appendectomy and hernia repair management in our center.

\section{CASE PRESENTATION}

A 2-year-old male came to the emergency department with a history of irreponible lump along with right scrotal tender 6 hours before admission and progressively increased. There is no specific sign of obstruction, dehydration or infection. His lump already presented since newborn but with age progression the reponible complain become more frequently. On physical examination, his abdomen was soft, non-tender and non-distended. Illustration of Amyand's Hernia can be seen in Figure 1. According to normal height and weight of 2-year-old boy (WHO chart) this patient was categorized as underweight nutrition profile (2 yo; 


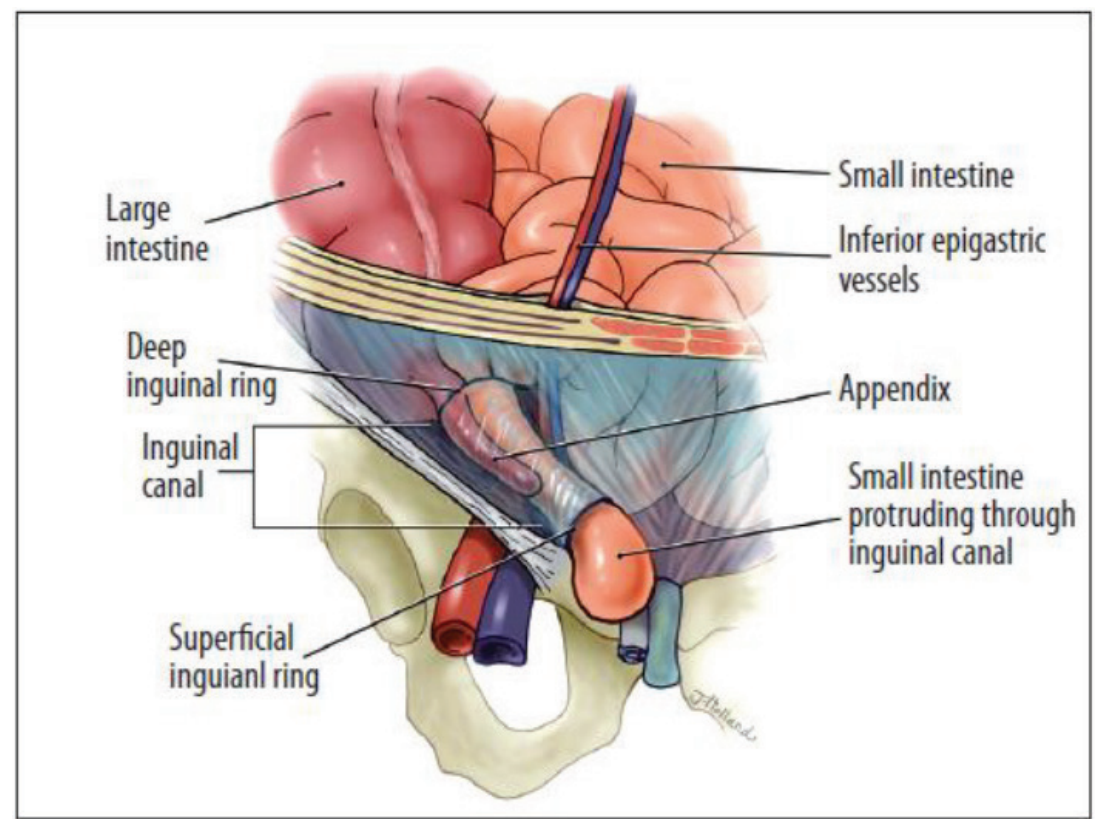

Figure 1. Illustration of Amyand's hernia. The appendix is shown within an indirect inguinal hernia, passing through both the deep and superficial inguinal rings and passing laterally to the inferior epigastric vessels

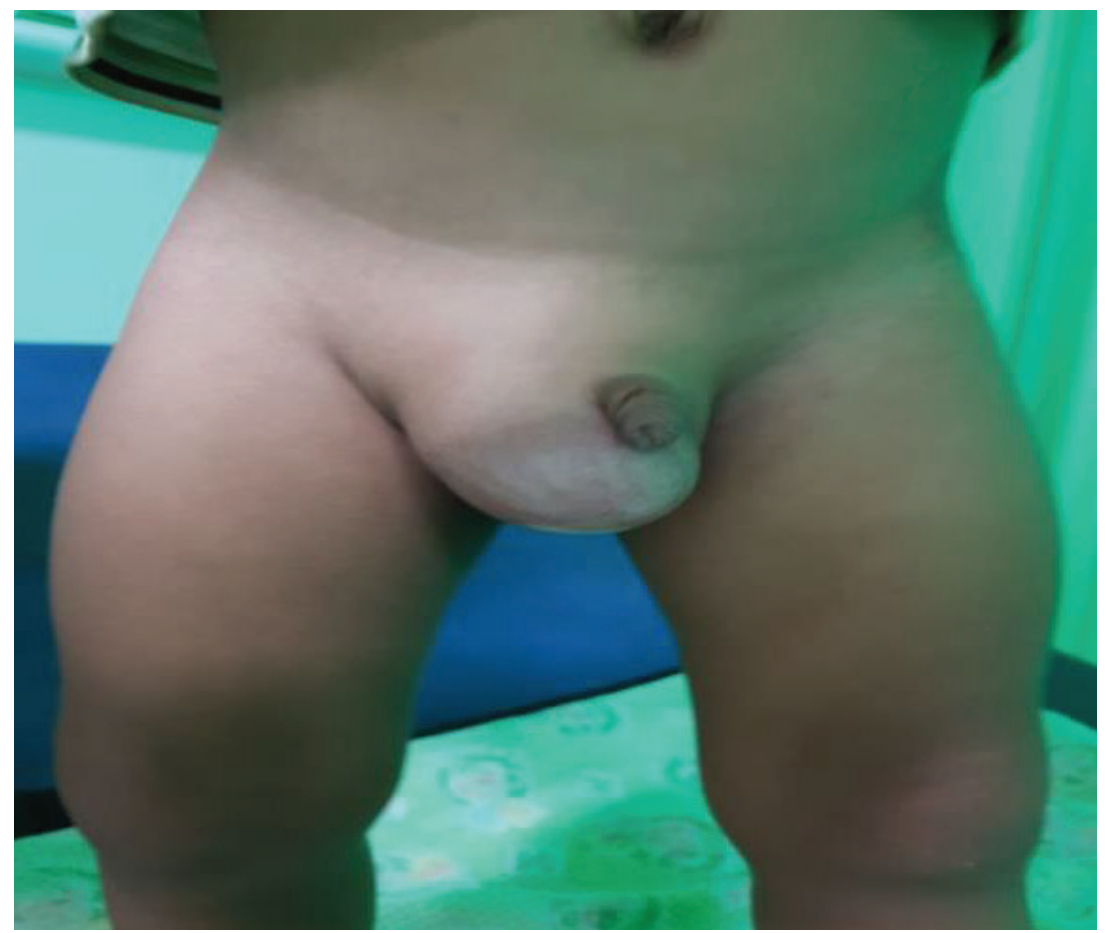

Figure 2. Clinical presentation at first admission

$71 \mathrm{~cm} ; 10,1 \mathrm{~kg}$ ) (Figure 2).

From laboratory blood test result we found leucocytosis $(18,3 \mu / \mu \mathrm{L}$; normal range 4,1-11 $\mu /$ $\mu \mathrm{L})$, slight anemia $(10,31 \mathrm{~g} / \mathrm{dL}$; normal range 13,5 $17,5 \mathrm{~g} / \mathrm{dL}$ ) and other blood test within normal limit.
Ultrasound sonography of inguinal and scrotal region described as right inguinal hernia (intestinal shadow with high possibilities as incarcerate case) (Figure 3).

At surgery, an inflammatory and edematous mass was found inside the inguinal canal. This mass was identified as the tip and body of the appendix and also small part of cecum (Figure 4). A small amount of clear fluid was noted in the peritoneum. The base of the appendix and cecum were healthy and the right testis was viable. An appendectomy was performed and a hernia repair was done. The neck of the sac then is closed with a suture ligature of fine silk and the sac amputated. Ordinarily, it is not necessary to open the sac during this process. However, if omentum or a loop of intestine is within the sac, the sac is opened, and these structures are returned to the peritoneal cavity before the neck of the hernia sac is closed. The distal portion of the sac is freed below the level of the external ring and excised. The testis and cord structures are repositioned into their normal anatomic bed if they have been disturbed, and an anatomic closure is performed. The aponeurosis of the external oblique and Scarpa's fascia are closed with interrupted sutures of fine silk. A subcuticular closure with fine absorbable suture is used in children (Figure 5). There is no exact correct operation technique due to clinical patient variety. But after 2-month post-operative care control, we didn't find any complication.

\section{DISCUSSION}

Amyand's hernia has been reported in patients ranging in age from 3 weeks to 92 years. ${ }^{4}$ The incidence of Amyand's hernia has varied in the literature, ranging from $0.19 \%$ to $1.7 \%$ of reported hernia cases. Amyand's hernia is 3 times more likely to be diagnosed in children than in adults, due to the patency of the processus vaginalis in the pediatric population. ${ }^{4}$

Clinical Presentation of an Amyand hernia most shown as appendix incarcerated and within an inguinal hernia may become inflamed, infected, or perforated. Although incarcerated, the appendix may also present as being entirely healthy. Inguinal herniations are found superior to the inguinal ligament, and superolateral to the pubic tubercle. They may be either direct or indirect. Direct inguinal hernias are found anteromedial and inferior to the inferior epigastric vessels; whereas indirect hernias protrude posterolateral and superior to the vessels. The appendix may be found in either of these as an Amyand's hernia. ${ }^{4}{ }^{4}$

Preoperative diagnosis of Amyand's hernia is not straightforward, and is generally an incidental 

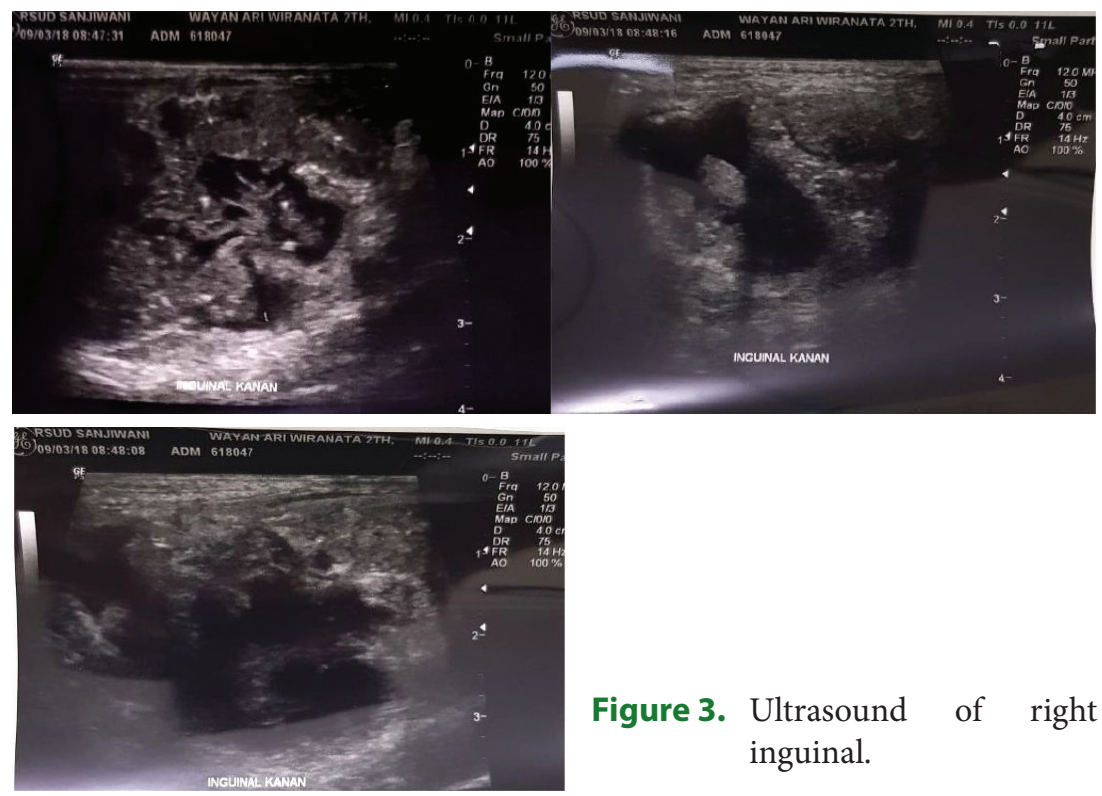

Figure 3. Ultrasound of right inguinal.

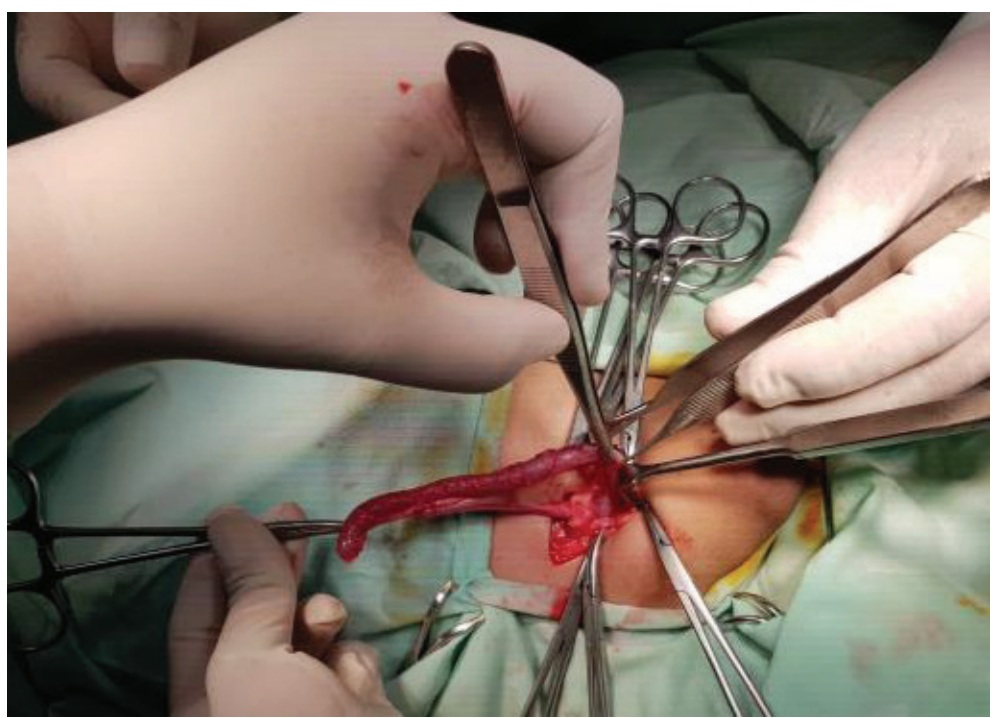

Figure 4. During operation, Appendix vermiformis was identified inside the scrotal sac.

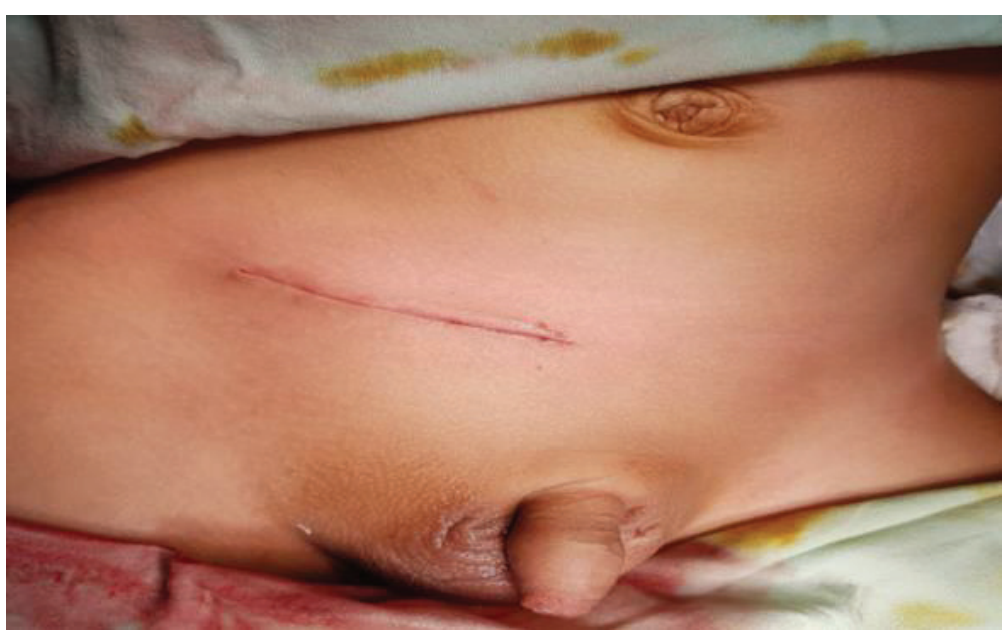

Figure 5. Post surgery wound closure finding during surgery.1,2,4 Abdominal exam, physical signs, lab results, and imaging are not always helpful in differential diagnosis. ${ }^{2,4}$ Common complaints include sudden-onset epigastric or periumbilical pain with localized tenderness in the right lower quadrant, combined with a tender irreducible mass in the inguinal or inguinoscrotal region..$^{3,4}$ This presentation however, often gives the clinical impression of a strangulated hernia, making clinical diagnosis of Amyand's hernia difficult. ${ }^{1,4}$

The management of such a hernia is dictated by the condition of the appendix within. Approach for surgery should be based on each clinical picture. Appendectomy through herniotomy with primary hernia repair will be the ideal treatment for such hernias in contrast to lower midline laparotomy which should be reserved for cases where complications are suspected.,8 Treatment includes herniorrhaphy with or without appendectomy depending on the vermiform appendix's inflammation status, the patient's general condition, and other factors. However, few guidelines on the approach to these situations with laparoscopic or robotic methods. In a case series done by Sahu et al. there patients with Amyand's hernia underwent laparoscopic transabdominal preperitoneal hernioplasty without appendectomy. Investigators found that laparoscopic repair, in the setting of Amyand's hernia, has several advantages including better visualization of the sac and the ability to inspect and repair a left sided inguinal hernia if present. ${ }^{5,7,9,13,14}$

The decision ultimately will depend based on many clinical aspects being kept in mind but as a general recommendation, literature review highlighted a classification system along with management options outlined by Losanoff and Basson, as described in Table 1.,10,11 Where appendix is found to be inflamed, suppurative or perforated, a Shouldice repair is recommended based on its low recurrence rate but any technical of operation could be done according to each case and the principle of the surgery which to removing the hernia sac, returned content to peritoneal cavity and locus minors closure. ${ }^{7,10,11,12}$

\section{CONCLUSION}

Amyand's hernia has been reported in patients ranging in age from 3 weeks to 92 years with the incidence $0.19 \%$ to $1.7 \%$ of reported hernia cases. Amyand's hernia is 3 times more likely to be diagnosed in children than in adults. Appendix itself could found intact or inflamed according to variety of each patient, but preventive appendectomy could be useful for further appendicitis. Any operation technique could be done according to each case 
Table 1. Classification of Amyand's Hernias After Losanoff and Basson

\begin{tabular}{|c|c|c|}
\hline Classification & Description & Surgical Management \\
\hline Type 1 & $\begin{array}{l}\text { Normal appendix with an } \\
\text { inguinal hernia }\end{array}$ & $\begin{array}{l}\text { Hernia reduction, mesh } \\
\text { repair, and appendectomy in } \\
\text { young patients }\end{array}$ \\
\hline Type 2 & $\begin{array}{l}\text { Acute appendicitis within } \\
\text { inguinal hernia, no abdominal } \\
\text { sepsis }\end{array}$ & $\begin{array}{l}\text { Laparotomy through hernia, } \\
\text { primary endogenous repair of } \\
\text { hernia, no mesh }\end{array}$ \\
\hline Type 4 & $\begin{array}{l}\text { Acute appendicitis, within an } \\
\text { inguinal hernia, abdominal } \\
\text { wall or peritoneal sepsis }\end{array}$ & $\begin{array}{l}\text { Laparotomy, appendectomy, } \\
\text { primary repair of hernia, no } \\
\text { mesh }\end{array}$ \\
\hline Type 4 & $\begin{array}{l}\text { Acute appendicitis within an } \\
\text { inguinal hernia, related or } \\
\text { unrelated abdominal pathology }\end{array}$ & $\begin{array}{l}\text { Manage as types } 1 \text { to } 3 \\
\text { hernia, investigate or } \\
\text { threat second pathology as } \\
\text { appropriate }\end{array}$ \\
\hline
\end{tabular}

and the principle of the surgery which to remove the hernia sac, returned content to peritoneal cavity and locus minors closure and for high note no mesh requires for this operation. 2 months of observation post-operative there is no complication was reported.

\section{CONFLICT OF INTEREST}

The author declares there is no conflict of interest regarding publication of this report.

\section{ETHICAL ASPECT}

Patient has received a signed inform consent and agreed for publication of the data in journal article.

\section{FUNDING}

Current report doesn't receive any specific grant from government or any private sector

\section{REFERENCES}

1. Kose E, Sisik A, Hasbahceci M. Mesh Inguinal Hernia Repair and Appendectomy in the Treatment of Amyand's Hernia with Non-Inflamed Appendices. Surgery and Research Practice. 2017;Article ID 7696385:1-4. DOI: https://doi. org/10.1155/2017/7696385.

2. Rikki S, Samita G. Amyand's HerniaPathophysiology, Role of Investigations and Treatment. A Journal of Clinical M e d i c i n e . 2011;6(4):321-424
3. Suha A, Kathryn L, Sathyan N, Mansoor A. Amyand's hernia managed with open repair and laparoscopic appendicectomy, Journal of Surgical Case Reports. 2017;11:1-3.

4. Ivashchuk G, Cesmebasi A, Sorenson EP, Blaak C, Loukas M, Tubbs SR. Amyand's hernia: A review. Med Sci Monit. 2014;20:140-146. DOI: 10.12659/ MSM.889873.

5. Sunil SB. Amyand's Hernia. Indian J Pediatric. 2009;76(8):854-855.

6. Murugesan MS, Rajasekaran MS. Amyand Hernia. IOSR Journal of Dental and Medical Sciences (IOSRJDMS). 2013;6(6):20-24.

7. Ikram S, Kaleem A, and Ahmad SM. Amyand Hernia: A Literature Review of the Diagnosis and Management of the Rare Presentation of the Wandering Appendix. Journal of Rare Disorders. 2018;4(1):1-4.

8. Kuru S, Bulgurcu A, Kismet K, Ertugrul E. Should an Appendectomy Be Performed for the Treatment of Amyand's Hernia with Non-Inflamed Vermiform Appendix? A Case Report and Review of the Literature. Visceral Medicine. 2013;29:51-54

9. Thomas JS, Frederick S, Dooniya S, Phillip LR. Robotic repair of Amyand's hernia: A case report. J Case Rep Images Surg. 2016;2:92-96.

10. Fonseca-Neto OCL, Lucena RCC, Lacerda CM. Amyand's hernia: inguinal hernia with acute appendicitis. ABCD Arq Bras Cir Dig. 2014;27(4):303-311.

11. Jonathan G, Luke GG. Amyand's hernia: a rare inguinal hernia. Journal of Surgical Case report. 2013;9:1-2.

12. Cardenas AM, Valencia CVP, Escarrega VHZ, Campos ACH, Murriz EM, Lizarraga CRL, Lopez $\mathrm{CAB}$. Amyand hernia: Case report and review of the literature. Annals of Medicine and Surgery. 2015;4(2):113-115.

13. Asma J, Habib B, Samer B, Fatma T, Rabiaa BA, Najib K. Amyand's hernia with appendicitis in the children: A delayed diagnosis. J Ped Surg Case Reports. 2016;13:6-7

14. Zollinger RM, Christoper EJ. Ninth editionZollinger Atlas Surgical Operation. USA: McGrawHill Professionals; 2010.

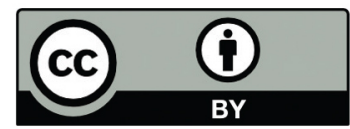

This work is licensed under a Creative Commons Attribution 